\title{
Anormalidad y Cultura Psiquiátrica: una indagación a partir de la Revista de Psiquiatría y Disciplinas Conexas, Chile, 1935-1957
}

\author{
Abnormality and Psychiatric Culture: an Inquiry from the \\ Revista de Psiquiatría y Disciplinas Conexas, Chile, 1935-1957
}

Marco Antonio León ${ }^{\star}, * *$

\begin{abstract}
RESUMEN
A partir del estudio de la Revista de Psiquiatría y Disciplinas Conexas, publicación especializada y con más de veinte años de continuidad (1935-1957) en Chile, se examina la relación entre la categoría de anormalidad y la manera como fue asumida y representada por las páginas de este medio académico. Desde la perspectiva del construccionismo y el análisis de contenido, se revisa su perfil editorial, su vinculación con el contexto de época, el papel asignado a los psiquiatras y la manera cómo dicha revista reprodujo y transmitió identidades estereotipadas. Palabras clave: Anormalidad; Psiquiatría; Revistas académicas; Cultura; Representaciones.
\end{abstract}

\begin{abstract}
This paper examines the relationship between the category of abnormality and how it was assumed and represented in the pages of the Revista de Psiquiatria $y$ Disciplinas Conexas, a specialized Chilean publication with over twenty years of continuity (1935-1957). From the perspective of constructionism and content analysis, we review its editorial profile, its link with the context of the time, the role assigned to psychiatrists and the way in which the journal reproduced and transmitted stereotyped identities. Keywords: Abnormality; Psychiatry; Academic journals; Culture; Representations.
\end{abstract}

\section{INTRODUCCIÓN}

La década de 1930 y los años siguientes presentan diversos aspectos interesantes de revisar en la historia sociocultural chilena, entre los cuales es posible destacar el desarrollo e imbricación que logra un modelo estatal de defen-

\footnotetext{
* Universidad del Bío-Bío, Chillán, Chile. mleon@ubiobio.cl <https://orcid.org/0000-0002-1326-5855>

** Esta investigación forma parte del Proyecto Regular DIUBB 2050349 IF/R (2020-2021).
} 
sa social a la par con uno de carácter asistencialista, la expansión del mercado cultural y editorial que involucró a diversos productos y públicos lectores, el reconocimiento académico y despliegue institucional que logró la criminología, así como la definición e individualidad que adquirió como especialidad la psiquiatría. Se trata, además, de un período influenciado por distintas ideologías, en lo político, por propuestas de "defensa de la raza", de higiene y control social, como asimismo por teorías que respaldan las ideas de degeneración y los planteamientos eugenésicos. Vale decir, es un escenario variado, complejo, pero no por ello menos interesante de abordar.

De acuerdo con lo indicado, estimamos pertinente una aproximación a dicho marco cronológico a partir de un cruce de perspectivas entre una historia sociocultural de la psiquiatría (Huertas, 2012; Scull, 2019) y una relacionada con los conceptos y la construcción impresa de relaciones de poder en torno al etiquetamiento de personas y a la reproducción de una categoría de clasificación (Castel, 2009; Ríos, 2016): la anormalidad (Foucault, 2000). Esta opción responde no solo a constatar un vacío historiográfico al respecto, sino también al hecho de hacerse necesario un acercamiento a los materiales impresos de la época - como una revista académica en nuestro caso -, pero considerados como productos culturales que, más allá de suministrar contenidos textuales o gráficos son, junto con su materialidad, vehículos de ideas, creencias, discursos y representaciones vigentes. De ahí que interese revisar hasta qué punto determinadas publicaciones, de naturaleza científica en lo específico, eran capaces de definir, estudiar, clasificar y convertir en objeto de investigación a personas y grupos. En tal sentido, creemos que la ciencia puede y debe ser entendida como una construcción sociocultural, pues los medios impresos a través de los cuales circulaba e interactuaba el conocimiento no eran neutros, ya que respondían a intencionalidades que, si bien no siempre eran explícitas, estaban igualmente presentes por medio de las perspectivas entregadas por los autores y equipos editoriales.

La elección de una publicación en particular: la Revista de Psiquiatría y Disciplinas Conexas (RPDC) se ha visto respaldada por tratarse no solo de la primera revista con continuidad de la especialidad psiquiátrica en Chile, sino por representar el carácter profesional, asociativo e institucional que logró la psiquiatría en el país para entonces. Es un medio que, en sus páginas, favoreció y fortaleció la discusión y debate de contenidos, defendió el carácter científico 
de la especialidad y destacó a los psiquiatras como actores relevantes ante el Estado y la sociedad (Araya, 2018, p. 179). Todo ello entregó identidad y proyección a una cultura psiquiátrica que - entendida a partir de la transmisión de ideas más allá de las fronteras, un discurso apropiable, soportes institucionales y un cuerpo de difusores - buscó visibilizarse a partir de criterios profesionales.

El vínculo entre la categoría de anormalidad y la cultura psiquiátrica que se explicitó mediante la revista puede tributar a la comprensión de problemáticas mayores como la generación, reiteración y circulación de las ideas y prejuicios que respaldaron los procesos de criminalización y etiquetamientos sociales. En esta perspectiva, el presente trabajo busca argumentar que si bien la anormalidad como etiqueta social no nació desde las páginas de la RPDC - pues hacía referencia a una construcción externa a este medio académico -, fue presentada y representada no solo como un fenómeno interpretable desde el punto de vista biológico, sino también a partir de criterios políticos y de poder como la vigilancia, el control, la higiene y prevención social, entre otros. Asimismo, fue transmitida mediante una retórica cultural que remitía a ideas, creencias, discursos e instituciones del período instaladas con el fin de objetivar las diferencias y peligrosidad de hombres, mujeres y niños de un sector social en particular.

Desde una perspectiva histórica y bajo la mirada del construccionismo social, esta investigación propone revisar las representaciones surgidas desde la revista seleccionada respecto de personas y grupos catalogados como anormales, a partir de los discursos allí utilizados para definirlos, estudiarlos y clasificarlos. En tal sentido, metodológicamente se ha realizado una revisión de contenidos, seguida de una organización y presentación de tal información para establecer el perfil de la revista y contextualizarla con otros referentes del período a modo de establecer puntos comunes con otras disciplinas y especialidades. De ahí que interese el lenguaje empleado, lo que se describe y lo que es posible de ser interpretado o connotado.

EL PERFIL DE LA REVISTA Y SU INSTALACIÓN EN EL MEDIO ACADÉMICO

La creación de la $R P D C$, en 1935, respondió no solo a la necesaria visibilidad que los médicos de la especialidad creían pertinente para difundir sus 
investigaciones y estudios, sino también a la construcción y afirmación de una identidad profesional que venía delineándose desde inicios del siglo XX. Ya entre 1917 y 1919 se había publicado la Revista de psiquiatría, neurología y medicina legal, la cual por diversos inconvenientes debió dejar de circular (Escobar, 1999, pp. 366-370), pero la inquietud de divulgación y afianzamiento de un camino más definido continuó vigente. En 1927, se logró la independencia de la psiquiatría respecto de la cátedra de neurología, lo que fue interpretado como un estímulo importante para la consolidación de la especialidad (Araya, 2018, p. 175). El papel que cobró desde entonces el Dr. Oscar Fontecilla fue vital para profundizar este hecho, ya que no solo se desempeñó como director de la naciente y emancipada cátedra, sino además fue uno de los gestores de la creación de la Sociedad de Psiquiatría, Neurología y Medicina Legal, en 1934, la que tuvo como órgano de difusión a la RPDC, desde cuyas páginas fueron publicadas las actas de dicha sociedad. Asimismo, fue el primer director de la revista en cuestión.

La $R P D C$ fue planteada desde un comienzo como una publicación de perfil académico, impresa bajo el alero de la Universidad de Chile en Santiago. Con la pretensión de llegar a todo el país, algo muy propio de la cultura de masas del período (Ossandón; Santa Cruz, 2005), buscó mostrar el protagonismo que cobraba la especialidad psiquiátrica, razón por la cual iba a la cabeza de otras disciplinas que se estimaban complementarias, tales como la neuropatología, la psicopatología, la psiquiatría forense, la higiene mental, la criminología y la psicología, entre otras. De ahí el nombre de Psiquiatría y disciplinas conexas, inspirado en un revista peruana de igual título con la cual mantenía comunicación e intercambio, al igual que con otras publicaciones contemporáneas del continente, con el propósito de debatir investigaciones y revisar las prácticas clínicas y terapéuticas del período, como bien lo apuntan Facchinetti, Cupello y Evangelista (2010, pp. 527-535). Desde su primer número se indicó el "propósito de fomentar en estas páginas el comercio intelectual, con nuestros colegas especializados de todos los países latinoamericanos" (Editorial, 1935, p. 1), poniendo a disposición de ellos la revista, pero recordando a los lectores que los médicos chilenos debían considerar a este medio como "su órgano propio".

Con un formato manejable, que osciló entre los 25 y los $19 \mathrm{~cm}$, de diagramación simple y sin color, con presentación de textos a una y dos columnas 
desde 1945, y con una extensión variable entre las 50 y casi las 190 páginas; se instaló en el medio académico mediante su distribución a las Facultades de Medicina del país. Dado que contaba con el auspicio de la Universidad de Chile, siendo editada por la Clínica Psiquiátrica de dicho plantel, como muchas revistas académicas esta no se vendía ni se especificaba tiraje, siendo integrada al presupuesto de la casa de estudios. En todo caso, ello no era un obstáculo para que pudiera llegar, más allá de su público objetivo de psiquiatras y doctores, a otros profesionales afines a las antes especificadas disciplinas conexas o también a profesionales del derecho, vinculados a la revista por medio de la medicina legal y la criminología. A propósito de este último aspecto, es preciso hacer notar que la $R P D C$ surgió en un contexto propicio para el desarrollo de las disciplinas psi (Vetö Honorato, 2015, p. 153), pero además para el fortalecimiento de otras instancias de investigación y difusión donde se integraban igualmente la psiquiatría, la psicología, la medicina y el derecho. Tal panorama era además apreciable en otros espacios geográficos y académicos de América Latina y el Caribe, donde también se estaba entendiendo que las problemáticas de salud no eran independientes de los contextos sociales e institucionales en los cuales tomaban lugar (Hochman; Armus, 2004; Miranda; Girón, 2009). En este escenario, se comprende, igualmente, la creación de un Seminario de Derecho Penal y Medicina Legal en la Facultad de Ciencias Jurídicas y Sociales de la Universidad de Chile, en 1934; del Instituto de Ciencias Penales, también dependiente de esa Universidad, en 1937; y de la Revista de Ciencias Penales, al año siguiente, que acogería investigaciones en las cuales, aparte de abordarse temáticas jurídicas, se presentarían igualmente enfoques interdisciplinarios y latinoamericanistas al momento de analizar la delincuencia y los comportamientos criminales.

De publicación trimestral, la RPDC editaba diversos trabajos de médicos nacionales y extranjeros, conferencias, presentaciones a congresos, reseñas de otras revistas latinoamericanas y obras del área, al igual que las actas de la antes citada Sociedad. Igualmente, y de acuerdo con el interés proyectado hacia la especialidad por su primer director, se hicieron numerosas referencias a las primeras Jornadas Neuro-Psiquiátricas del Pacífico realizadas en Santiago en 1937. Un papel destacado en dicho evento fue el que tuvo el Dr. Isaac Horvitz, para entonces profesor agregado de psiquiatría, quien no solo fue subdirector de la revista, sino además el encargado de la publicación de las actas de las 
jornadas, que congregaron a especialistas de Argentina, Ecuador, Perú y Uruguay, por medio de las prensas de la Universidad de Chile (Horvitz, 1938). Así, paulatinamente, se construían las primeras redes intelectuales en la materia.

Luego de la trágica muerte de Fontecilla en 1937, en manos de uno de sus pacientes del manicomio, diversos médicos asumieron la dirección de la revista, tales como Arturo Vivado (en 1938) e Ignacio Matte (en 1949), quienes encontraron como redactores y colaboradores a los doctores Víctor Arroyo, Manuel Francisco Beca, Sergio Rodríguez, Carlos Carrillo, Guillermo Gil y Juan Marconi, entre otros. En términos gruesos, la revista buscó ser parte de una red de publicaciones en el continente que intentaba mostrar a los ojos de los especialistas, y a los lectores interesados en estas temáticas, que la realidad psiquiátrica latinoamericana - y chilena en particular - era bastante distinta a la estadounidense y la europea (Araya, 2018, p. 176). De este modo, la generación de conocimientos locales no debía entenderse como una empresa aislada o solo receptiva, lo que guardaba sentido con el temprano interés por la construcción y circulación de dichos conocimientos en esta y otras áreas, como bien lo han expuesto y teorizado para comprender la dinámica global y transnacional de la ciencia moderna autores como Raj (2007) y Krige (2012), entre otros. Hasta 1952, la RPDC mantuvo su nombre original, pero desde esa fecha y hasta 1957, que es cuando desaparece, empezó a denominarse solo como Revista de Psiquiatría, especificándose ahora que era publicada por la cátedra de Psiquiatría de la Universidad de Chile, pero conservando los criterios y equipo editorial de la etapa anterior.

Durante la década de 1940 y hasta mediados de los años 1950, no hubo grandes cambios en su formato. Con una lógica editorial centrada en la presentación de contenidos textuales y escasas fotografías, la revista mostró un amplio abanico de perspectivas para abordar la especialidad, no haciendo una opción explícita, dando lugar en sus páginas al psicoanálisis, y a posturas con énfasis organogénicos, psicogénicos, etc. Las estrategias editoriales que se pueden apreciar en sus 22 años, aparte del evidente soporte empírico requerido para respaldar las argumentaciones de los autores, apuntan en más de una ocasión a aspectos como la reiteración de ideas respecto del papel social del Estado, los doctores y psiquiatras; al acento en la dualidad entre lo normal y lo patológico - lo que aparece explícita o implícitamente en los artículos publicados - y al amplio uso de los criterios de autoridad en relación con espe- 
cialistas del área, en particular con estadounidenses y europeos. De ahí las frecuentes citas y referencias bibliográficas que se insertaban bajo el criterio de actualización de las perspectivas de estudio. Todo ello creó también un discurso orquestado en que texto e imagen, en los pocos casos en que se combinaron, reforzaban una idea.

Si bien fue concebida como una revista abierta a recibir colaboraciones de todo el país, por lo general los aportes se concentraron en médicos de Santiago - siendo una buena parte de ellos formados en la misma universidad que la publicaba -, cuyas investigaciones teóricas y prácticas, retratadas en más de una oportunidad en la reproducción de historias clínicas, provenían de su desempeño profesional en instituciones como la Clínica Psiquiátrica de la Universidad de Chile, el Manicomio Nacional, el Instituto Médico Legal, la Penitenciaría de Santiago y la Dirección General de Protección a la Infancia y Adolescencia. La vinculación de los autores con espacios de control social directo e indirecto determinó que, junto al lenguaje técnico ocupado en muchos artículos, emergieran términos como los de "normal", "anormal", "anormalidad", "degeneración", "peligrosidad", "higiene" y "defensa social"; conceptos que si bien tenían una base en la biología, eran empleados igualmente fuera del ámbito disciplinar de la medicina en los discursos de la prensa y las autoridades políticas, judiciales y carcelarias del período (León, 2015, pp. 133-168). Por ello, concordamos con el hecho de que el estudio de publicaciones como la que nos interesa constituye una interesante vía de entrada a todos estos temas, siendo un "reservorio de información valiosa para detectar e identificar sensibilidades epocales en relación a conductas que aparecieron como amenazantes a ciertos parámetros construidos desde la elite dirigente" (Dovio, 2013, p. 1250).

\section{PSIQUiATRÍA Y DEFENSA SOCIAL}

Si bien la creación de etiquetas sociales como las de normalidad y anormalidad no se hizo por medio de la revista examinada, ni tampoco solo mediante la especialidad psiquiátrica, como lo explicaran en su momento Canguilhem (1971) y Foucault (2000), la publicación las asumió como algo aceptado desde sus inicios. Lo normal se entendió a partir del consenso, algo que todos hacían y que era interpretado como correcto, sano y ordenado; mientras que su antítesis se vinculó a lo diferente, lo malsano y perturbador. 
De ahí que la norma no solo determinara la diferencia específica entre normal y anormal, sino que estableciera "los criterios por los cuales un sujeto se convierte en un asunto a corregir por el aparato psiquiátrico y de salud pública” (Vásquez, 2012, Apud Camargo; Ried, 2019, p. 67). Por supuesto, en diversos artículos se abordó directa e indirectamente el tema, pero hasta donde nos consta nunca se discutió o debatió tal categorización, que fue asumida como válida en la medida que hacía sentido para los especialistas al considerar que cualquier alteración mental y conductual podía y debía ser examinada a partir de su asociación con lo patológico, lo enfermo y - en los casos más extremos - con lo peligroso. Sin embargo, la construcción de esta categorización no se quedaba solo en ello, pues involucraba consideraciones de carácter social al asociar, de manera prácticamente mecánica, la anormalidad con una condición de clase, la de los pobres (Peset, 1983). En tal sentido, la anormalidad buscó ser definida y catalogada a partir de referencias científicas, pero detrás de ella había creencias y sentidos comunes o estereotipos que no eran ajenos al cuerpo social ni tampoco a los psiquiatras, como el hecho de que se considerara como enfermos a todos aquellos que tenían un patrón conductual distinto del establecido por las autoridades políticas, sociales y médicas. Eran "enfermos" a los que había que curar - si era posible -, de ahí su patologización que justificaba el poder intervenirlos, aislarlos, encerrarlos, estudiarlos y exponerlos, por ejemplo, a través de investigaciones como las que aparecían en la $R P D C$, las cuales, como se señaló, se esperaba que circularan en el país y en el extranjero. Para esto último, el canje de publicaciones era clave, ya fuese por asistencia a congresos o por correo.

Igualmente, cobró fuerza la creencia de que, entre los pobres, los síntomas de problemas conductuales, psicopatologías y enfermedades mentales eran más evidentes. Si se revisan los artículos de la revista, se constata que los sujetos/objetos de estudio provenían de los sectores populares de la sociedad urbana y, en ciertas ocasiones, de una suerte de clase media, pero más cercana al mundo popular. Lo indicado es notorio cuando se aborda el tema de la infancia y juventud (Vila, 1939, pp. 181-190), de la asistencia psiquiátrica en general (Vivado; Larson; Arroyo, 1939, pp. 155-172), del alcoholismo (Arroyo, 1941, pp. 27-45), de la delincuencia y la homosexualidad (Brücher, 1941, pp. 92-100; Carrillo; Whitting, 1952, pp. 129-141; Marconi et al., 1953-1955, pp. 11-16), al igual que en la reproducción de diversos historiales clínicos (Beca; Larraguibel, 
1948, pp. 3-10; Carrillo; Rodríguez, 1950, pp. 75-86; Vergara; Horvitz, 1945, pp. 115-121), presentados estos últimos como base para estudios en progreso o como una muestra de la acción efectiva y práctica de los psiquiatras a cargo. Reforzaba estos contenidos un sentido común en el cual los anormales eran pobres - o sus cercanos - y enfermos. Pero dicha asociación debía incluir un eslabón más en esa cadena interpretativa: el de la peligrosidad.

Tal concepto iba de la mano con el de higiene social, pues el discurso de los psiquiatras también recogía el planteamiento de que para evitar dicha peligrosidad había que ser proactivo y ello implicaba un diagnóstico claro y certero. En tal labor el papel del Estado y sus representantes era clave, dado que - recuérdese - los psiquiatras que escribían en la revista pertenecían o trabajaban en su mayoría en instituciones directa e indirectamente vinculadas a la administración pública. Esta era una tarea que debía ser explicitada y así lo fue por la $R P D C$. Desde tal perspectiva, pueden comprenderse mejor las palabras del Dr. Isaac Horvitz, enfatizando ideas que volvían útil el uso de la categoría anormal en función del resguardo y prevención del vicio, la improductividad y la peligrosidad por medio del trabajo, entendido este último con un propósito terapéutico y funcional. De ahí su propuesta de crear "colonias de epilépticos, de alcohólicos, toxicómanos" y de aprovechar "a los parkinsonianos post encefálicos en algún trabajo. Actualmente estos últimos son parásitos de la Caja [de Seguro], pues ésta se limita a concederles la pensión de invalidez" (Horvitz, 1936, p. 13). Sin embargo, el criterio de concebir el trabajo con fines preventivos y productivos tampoco estuvo ajeno a la niñez y la adolescencia. El Dr. Gustavo Vila, interesado en tales temáticas, planteaba que a "todos estos anormales que constituyen el estado peligroso de la infanto-juvenilidad se les destinará a los Hogares Campestres consistentes en sitios con varias hectáreas de terreno cultivables, con casas pequeñas, aisladas" (Vila, 1939, p. 187), pues así se creía que era posible mejorar la salud física y moral de una población.

Detrás de buena parte de estas ideas y creencias estaba el positivismo, el cual, si bien había experimentado diversos cuestionamientos por sus posturas deterministas, continuó vigente en la medida que sirvió de respaldo para intervenir a individuos y grupos que se consideraba que alteraban el orden, la disciplina y la organización social. La defensa de la sociedad buscó legitimarse como una teoría que tenía pretensiones científicas, pero también de corte sociológico (Bustos, 1983, p. 17), pues justificaba la vigilancia y el control en aras 
de la prevención bajo la excusa de una neutralidad u objetividad entregada por la ciencia (Mallereal, 2012). En esta lógica, la especialidad psiquiátrica cobró un papel de importancia, pues a ella le correspondía, de acuerdo con lo expuesto en las páginas de la RPDC: "la misión de defensa social apartando de su seno a los elementos peligrosos o antisociales; y por otra, tratar a tales elementos en su calidad de enfermos mentales" (Vivado; Larson; Arroyo, 1939, p. 160). Una opinión similar tenía el Dr. Waldo Iturra, para quien, conocidas las perversiones, "y diagnosticadas [estas] clínicamente debemos aceptar que la doctrina de la peligrosidad es la mejor norma para enfocar el problema de la responsabilidad de los perversos esenciales" e imponer así "medidas de segregación social ilimitada" en "verdaderas instituciones profilácticas del delito" (Iturra, 1940, pp. 407-408).

Lo indicado tomaba sentido en un escenario en el cual los doctores ganaban protagonismo más allá de su disciplina, tal como se vería con la creación, en 1936, del Instituto de Clasificación y Criminología de Chile, bajo la dirección del Dr. Israel Drapkin; de la clínica de conducta establecida ese mismo año en la Escuela Especial de Desarrollo, bajo la labor del Dr. Guillermo Agüero; o con el impulso a estas mismas ideas entregado por el Dr. Luis Cubillos en diferentes publicaciones (Vetö Honorato, 2015, pp. 210-217). De hecho, fue frecuente encontrar trabajos de Cubillos en las Jornadas Neuro-Psiquiátricas, junto a Drapkin, en la Revista de Ciencias Penales, en la RPDC y en cursos, junto a Agüero, para el perfeccionamiento del personal de prisiones (Agüero; Cubillos, 1941). Así comenzaba a perfilarse una modalidad interdisciplinar y redes de intercambio de ideas y propuestas entre otras instituciones y publicaciones contemporáneas.

Las inquietudes de intervención también guiaron otras investigaciones aplicadas a grupos específicos de población, como la realizada a mediados de 1941 a delincuentes homosexuales en la Penitenciaría de Santiago, quienes fueron sometidos al test de afectividad de Rorschach, aparte del test miokinético de Mira con el propósito de estudiar directamente su psicomotricidad, es decir, su nivel de agresividad (Brücher, 1941, p. 92). Al respecto, varios especialistas suscribían el planteamiento de una perversión constitucional que descansaba en un criterio determinista, pues provenía no solo de las malas influencias de un ambiente familiar y social deteriorado, sino además de una carga hereditaria, tal como se planteaba al momento de revisar algunas historias clínicas de ho- 
micidas y esquizofrénicos (Carrillo; Rodríguez, 1950, pp. 75-86; Vergara; Horvitz, 1945, pp. 115-121). Volvían así a cobrar fuerza las teorías de la degeneración, planteadas desde el viejo continente en el siglo XIX (Pick, 1999), pero que eran actualizadas a partir de la necesidad de explicar una perversidad esencial: "la escuela lombrosiana y de sus discípulos y continuadores que pretendieron establecer el hombre criminal, como los propugnadores franceses de la degeneración mental, Morel, Magnan, todos están de acuerdo en aceptar que de este grupo de individuos salen el mayor porcentaje de criminales constituyéndose en los sujetos recidivantes y delincuentes de repetición" (Iturra, 1940, p. 402). A ello se unían propuestas eugenésicas que, si bien reforzaban el discurso de defensa social y peligrosidad, aparecían de modo menos explícito, salvo en el caso del Dr. Horvitz, para quien era preciso interrumpir los embarazos cuando la salud física y mental del "nuevo ser" ofrecía "pocas garantías de utilidad social” (Horvitz, 1936, p. 12; Letelier, 2009, pp. 77-91).

Junto a estos contenidos, aparecían en la RPDC artículos de reflexión, redactados por doctores, en que cobraba protagonismo el tema racial al momento de examinar el alcoholismo en Chile, indicándose como antecedente "la tradición ancestral de nuestros grupos aborígenes". Ello, según el Dr. Juan Marconi, dado que "en las sociedades primitivas es muy raro encontrar lo que entre nosotros se llama ingestión moderada de alcohol [...] la comunidad, o por lo menos todos los hombres, beben en forma colectiva y, habitualmente, en una medida que nosotros consideramos excesiva" (Marconi, 1952, pp. 5, 12-13). Se naturalizaba así la asociación entre indígena y alcoholismo, vicio y peligrosidad. Vale decir, aparte de la información y circulación de investigaciones e ideas científicas, las operaciones de lectura realizadas por los lectores al momento de abordar uno o más de estos artículos no podían ser ajenas a las ideologías, prejuicios y estereotipos de su marco contextual como lo ha explicado Bourdieu (1999).

\section{OBJETIVANDO LAS DIFERENCIAS Y SU PELIGROSIDAD}

El estudio de los etiquetamientos sociales fue objeto de la sociología de la desviación desde finales de la década de 1950, la cual, influida entre otras corrientes por el interaccionismo simbólico, buscó explicar los procesos de criminalización vigentes en las sociedades contemporáneas. Dicha mirada, 
que encontró como principal referente la investigación de Becker (2009 [1963]), puede ayudarnos a comprender la asignación de determinadas adjetivaciones, entendidas más bien como construcciones sociales de sentidos que terminaron atribuyendo características e identidades a sujetos específicos del cuerpo social. De hecho, las referencias a la anormalidad cobraron fuerza desde fines de los años 1930 e inicios de la nueva década. Ello coincidió con la proliferación de instituciones y profesionales que asumieron y respaldaron la instalación de dicha categoría en disciplinas como el derecho y la medicina, y en especialidades como la criminología y la psiquiatría. Este ambiente de interdisciplinariedad y nuevos especialistas encontró respaldo en la denominada Escuela positivista cuya versión criminológica, desarrollada desde el siglo anterior por Cesare Lombroso, logró reactivación gracias al trabajo vinculante que empezó a tener una parte del mundo del derecho con las disciplinas psi (Vetö Honorato, 2015, p. 153). Junto a ello, estuvieron presentes ideas como las del higienismo social que - muy de la mano con la defensa social respaldaron la prevención, pero también la vigilancia, el examen, la medición e intervención hacia aquella población que tuviese una conducta peligrosa o que pudiese llegar a tenerla, presuponiéndose así futuros actos de violencia, delitos y crímenes.

Como se indicó, la anormalidad fue concebida como un fenómeno que tenía una naturaleza ontológica (algo dado), tal como la interpretaba la criminología positivista, y que era definida desde las agencias policiales, judiciales y carcelarias, pero también asumida por los profesionales de la medicina, con clara orientación social, y de la especialidad psiquiátrica en particular. Dicha mirada se mantuvo por la $R P D C$ al momento de abordarla, al igual que a los sujetos (hombres, mujeres, niños/as, ancianos/as) contemplados dentro de ella. Estas ideas y creencias descansaban en un consenso acerca de valores interpretados como esenciales: propiedad, integridad física, libertad, etc., los cuales se visualizaban vulnerados por delincuentes y por quienes, además, aparecían catalogados como anormales aludiendo a sus carencias físicas, mentales, morales y económicas. Bien lo habían sintetizado los doctores Cubillos y Drapkin: "el acto delictuoso es el producto de condiciones físicas y psíquicas del hombre delincuente y de factores económicos y sociales" (Cubillos; Drapkin, 1938, p. 634). Los autores de la revista utilizaban en sus diagnósticos las categorías de anormalidad, degeneración y peligrosidad sin entrar a dar una mayor defini- 
ción o explicación de las mismas, apropiándose de "etiquetas" que eran asumidas como establecidas y legitimadas por sus colegas y lectores.

Buena parte de tales planteamientos, y otros similares que combinaban prevención, educación, control, rehabilitación/regeneración; se plasmaron en el Segundo Congreso Latinoamericano de Criminología que tomó lugar en la ciudad de Santiago en 1941 (Ruperthuz, 2015, pp. 192-196), reafirmando cómo los intercambios y la interdisciplinariedad ya "eran habituales en ese campo y, a decir verdad, obligatorios” (Vetö Honorato, 2015, p. 205). Las ideas expuestas, junto con los prejuicios y la generación o confirmación de estereotipos que conllevaban, no serían ajenas a la revista examinada, pues como se desprende de la lectura de diversos trabajos allí publicados, las personas que actuaban de manera violenta lo hacían porque sus acciones respondían más bien a fuerzas biológicas y sociales que estaban más allá de su control (Beca, 1938, pp. 12-30; Beca; Larraguibel, 1948, pp. 3-10; Rodríguez, 1952, pp. 3-33). De ahí que debiesen ser controlados por otros, por quienes tenían como respaldo a la ciencia, entendida a partir de su neutralidad, la cual debía encargarse de encontrar significado a las acciones violentas, a los hechos de sangre y dar respuestas a la sociedad respecto de quienes podían ser sanados y reintegrados y quienes no. Había que defender el orden y la tranquilidad social.

En los diagnósticos, investigaciones y análisis de casos reproducidos en la revista se apreciaba que, en la mirada psiquiátrica y cercana a la criminología, la anormalidad no solo era definida a partir de la debilidad mental, la psicosis y las perversiones, sino además contemplaba a la histeria, las neurosis y personalidades psicopáticas. Cobraba aquí importancia el papel de la herencia y la prevención en la transmisión de las constituciones patológicas, aunque el tema eugenésico no aparecía de un modo explícito. Más bien se especificaban, por ejemplo, medidas de seguridad predelictuales para el apoyo y control de la infancia y adolescencia, posibles de abordar por la implementación de clínicas de conducta, experiencia aplicada en la Escuela Especial de Desarrollo de Santiago y que encontró respaldo en doctores como el psiquiatra Guillermo Agüero, el pediatra Alberto Gallinato y en frecuentes colaboradores de la RPDC como Víctor Arroyo, Gustavo Vila y Luis Cubillos (Agüero; Cubillos, 1938, pp. 38-50; Cubillos, 1946, pp. 96-98). Detrás de dicha experiencia se combinaron ideas del higienismo social y de psicoanalistas europeos, promoviéndose "un sistema de atención basado en la 'observación de la vida emocional o 
afectiva"” (Vetö Honorato, 2015, p. 196). En una línea interpretativa similar, el doctor Vila consideraba que el débil mental, no degenerado, debía ir a un hogar de reeducación. Mientras, el "resto de los anormales son los sujetos candidatos a la delincuencia. Nuestra legislación actual es tan primitiva en este sentido, que se espera que el joven delinca para castigarlo y por añadidura ensaya reformarlo" (Vila, 1939, p. 187). Para ellos, la opción era la creación de hogares campesinos.

Para los adultos, se planteaba la creación de "servicios sociales u otras instituciones para descubrir los perversos incipientes instalándolos en clínicas de conducta u otros establecimientos adecuados que serían verdaderas instituciones profilácticas del delito, mediante investigaciones de la ascendencia, del medio familiar o escolar, etc." (Iturra, 1940, pp. 407-408). Entre las medidas postdelictivas, se esperaba un mayor apoyo del psicoanálisis, respaldado igualmente desde las páginas de la revista. Según el doctor Manuel Francisco Beca, uno de sus principales defensores para entonces: "En un establecimiento adecuado de readaptación o reeducación, podrá en cambio [el psicoanalista] desarrollar ampliamente su labor, con un psicoanálisis prolongado, o abreviado, según convenga [...] en uno u otro caso, en la cárcel o en el instituto especial, la intervención del psicoanalista tendrá por objeto conseguir esa adaptación social que decayó o nunca existió en el delincuente en tratamiento" (Beca, 1940, p. 431).

Los mencionados criterios estuvieron detrás de la nominación y caracterización de la anormalidad, pero con el trascurso de los años, y en general por el aumento de la percepción de inseguridad frente al delito y el crimen proyectado por varios medios de comunicación y el discurso de distintas autoridades (León, 2015, pp. 134-148), las ideas respecto de la prevención y defensa social se extremaron mediante una nueva ley (la n. 11.625 del 4 de octubre de 1954) denominada de "estados antisociales". Tal cuerpo legal mostró que la cara sancionadora del poder político (dado que establecía internamiento obligatorio, prohibiciones y multas) seguía vigente, como en el siglo XIX, en particular al momento de tipificar las figuras delictivas, dentro de las cuales se incluyó a ebrios y toxicómanos junto a vagos y mendigos y a los explotadores e inductores de la homosexualidad, aunque curiosamente no se incluyó a esta última dentro de dichas figuras. En tal escenario, la anormalidad terminó vinculándose a lo antisocial. Todo ello, con el propósito de controlar y casti- 
gar, pero también prevenir su peligrosidad social. Lo explicado guarda relación con los artículos que aparecieron después de esa fecha en la revista al momento de estudiar a los alcohólicos, las toxicomanías y su peligrosidad (Marconi et al., 1953-55, pp. 11-16; Marconi, 1956-57, pp. 6-22; Mardones; Varela, 1956-57, pp. 83-88).

El reconocimiento público de acciones y conductas interpretadas como amenazantes o dañinas para las personas, por parte de los agentes policiales, judiciales, carcelarios y por profesionales y especialistas del ámbito del derecho y la medicina, entendidos a partir de una supuesta neutralidad, pero con un compromiso social, definió en buena medida las reacciones y la atribución de significados hacia la anormalidad. De ello también dio cuenta la RPDC en artículos publicados por doctores que no solo eran parte de dicho contexto, sino que igualmente participaban y estaban en sintonía con él. Al momento de relacionar tal categoría o etiqueta social con quienes eran adscritos a ella, se confirmaban ideas, creencias y prejuicios, según veremos a continuación.

\section{Figuras INQUiETANTES}

Se etiquetaba como anormales a quienes presentaban desórdenes mentales, conductuales y cuyas acciones podían ser catalogadas como violentas contra sí mismos o contra otros. Ello cobraba significado dentro del contexto de época que hemos especificado y más aún si la tipificación de dichas conductas podía configurar un delito o un crimen, según la ley penal vigente. Para la $R P D C$, una cuota significativa de influencias se encontraba en la carga hereditaria presente en quienes atentaban contra la vida, la propiedad y el orden social; pero también se colocaban en el tapete otras causas como los malos ambientes familiares, entornos sociales degradados, problemas económicos y la presencia de vicios, como el alcoholismo y las toxicomanías, que adquirían progresivamente mayor protagonismo. Aspectos todos ellos posibles de evidenciar a partir de la reconstrucción de historias de vida que permitían la mirada clínica, el diagnóstico de la enfermedad y el rescate de la individualidad, como indicara Foucault (1991, pp. 46-62). De ahí que en las páginas de la revista aparecieran con bastante frecuencia referencias a alcohólicos, niños mongoloides, pasionales patológicos, delirantes, esquizofrénicos, alucinantes, adictos, débiles mentales, paranoicos, neuróticos, psicópatas, oligofrénicos y 
homosexuales; figuras amenazantes subsumidas dentro de la anormalidad, aunque con disímiles niveles de enfermedad y peligrosidad.

Este perfil de anormales, detectable también en varios artículos de investigación, cobró interés por asociar la noción de enfermedad o patología a una condición de clase e igualmente a una apariencia - profundizándose así un proceso ya explorado por Correa (2012) para el siglo XIX -, aspecto este último menos apreciable dado que la revista no incorporó, por lo general, fotografías. Pero al hacerlo inducía al lector a establecer las asociaciones antes mencionadas, aunque estas no se explicitaran. Desde dicha perspectiva, el trabajo del Dr. Sergio Rodríguez, respecto de la "mímica en la esquizofrenia", puso en evidencia lo señalado al constituir, de acuerdo con nuestra revisión, la única exposición de historias clínicas acompañadas por imágenes, sin identificar, de casos provenientes del Manicomio Nacional (Rodríguez, 1943, pp. 3-80).

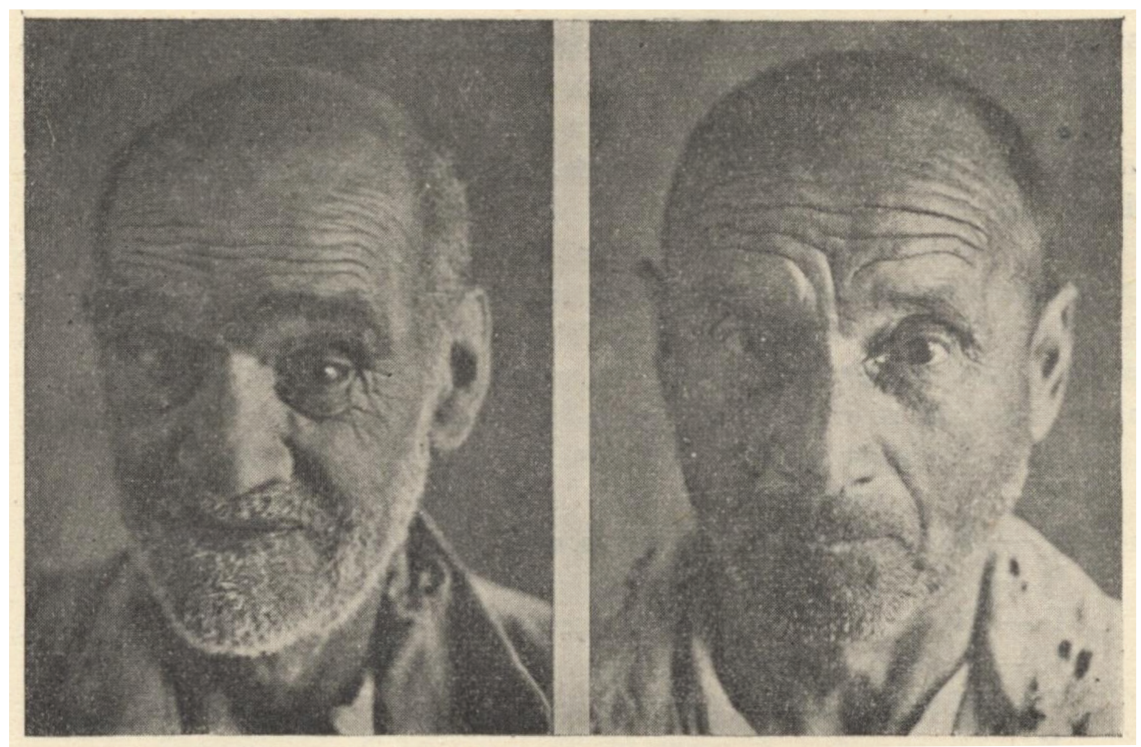

Fuente: Rodríguez, 1943, p. 29. 


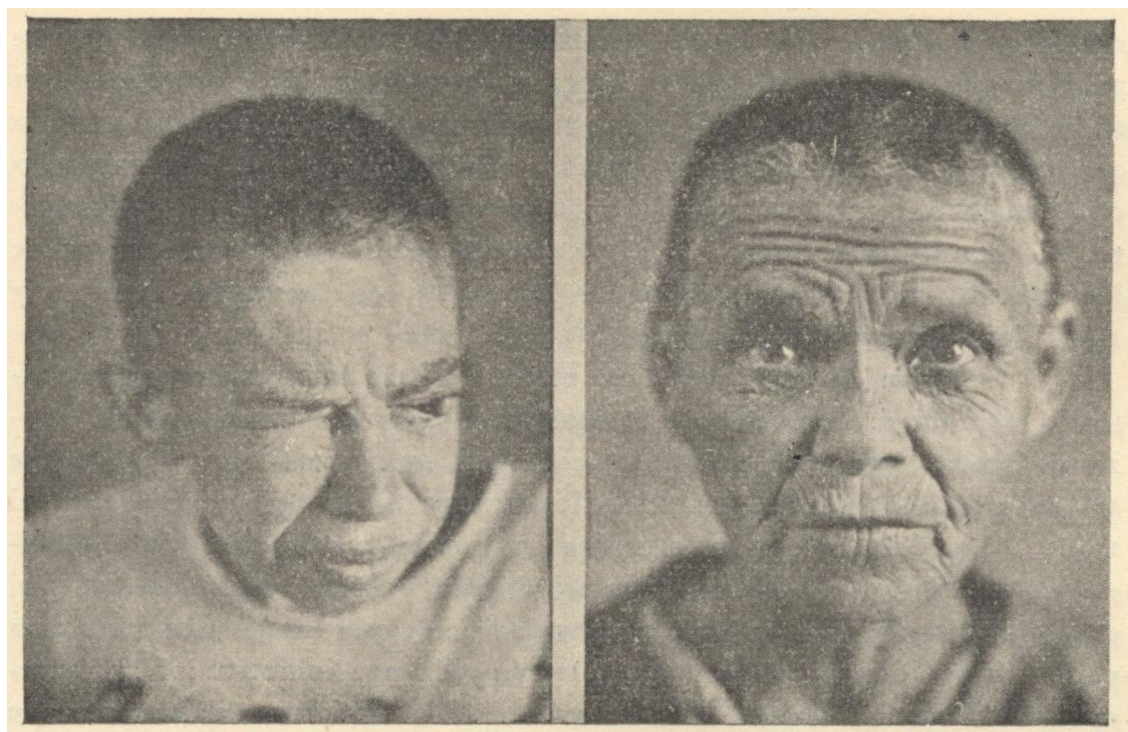

Fuente: Rodríguez, 1943, p. 35.

De distintas edades y sexos, aunque no siempre especificándose su oficio o profesión, estos casos trazaron un recorrido por la historia vital de distintas personas con diversos niveles de anormalidad. Las narraciones enfatizaron ambientes sociales y familiares degradados y afectados por vicios, aparte de considerar temas genéticos que volvían a ser reconducidos en la interpretación entregada a una cadena hereditaria que los retrotraía a sus padres y abuelos. En tales ejemplos, y en otros presentados en la revista, se trataba de buscar una explicación a los actos violentos que habían llevado a las personas examinadas a la cárcel y desde ahí al manicomio. Y ello era relevante dado que tales diagnósticos permitían establecer si en realidad existía alienación y, por ende, si el acusado era imputable o no del delito. De ahí la necesidad de detallar la existencia de "un temperamento neurótico y de trastornos mentales de naturaleza tóxica alcohólica presentada en tiempos del crimen", como expresaba el Dr. Iturra al momento de revisar un caso de rabia curado en un empleado municipal (Iturra, 1936, p. 48); o de explicitar el perfil de un delirante que se sentía "Víctima de persecuciones de parte del Presidente de la República, de Instituciones y de gremios. [He ahí el] comienzo del delirio de enormidad: ha dado un mensaje divino" (Arroyo, 1941, p. 36). 
Con el paso del tiempo esta mirada preventiva y controladora se hizo más explícita para evitar la peligrosidad de hombres, mujeres y niños, recomendándose establecimientos especiales: "para los alcohólicos y toxicómanos, el Instituto de Reeducación Mental; para los epilépticos no dementes, la Colonia de Epilépticos; y para los oligofrénicos, irreductibles, perversos, entre otros, el Asilo para deteriorados infantiles, con un carácter mixto" (Vivado; Larson; Arroyo, 1939, pp. 170-171). Ideas y estereotipos respecto de los anormales, - como seres marcados por una enfermedad que, aparte de tener una carga hereditaria, podía ser transmitida o contagiada, especialmente entre los pobres -, se mantuvieron no solo entre los especialistas, sino además en la institucionalidad que debía hacerse cargo, por ejemplo, de los homosexuales. Así lo indicaba el Dr. Brücher en un informe: "Estos homosexuales [con quienes había trabajado en una investigación] serán trasladados al Presidio de Pisagua, en donde se agrupan esta clase de delincuentes, medida que adoptó la actual Dirección General de Prisiones para evitar contaminaciones e incidentes entre los penados comunes con la convivencia de homosexuales" (Brücher, 1941, p. 94). Concluía asimismo que ellos "carecen de la agresividad homicida que es dependiente en gran parte de una buena actividad genital masculina. Las mujeres y los homosexuales son menos agresivos" (Brücher, 1941, p. 100). Por supuesto, la evidencia empírica para respaldar dicha afirmación no se explicitaba.

El factor hereditario era puesto en escena cuando se entregaban explicaciones respecto de los alcohólicos y las consecuencias que traía para el país su aumento, afectando el progreso y crecimiento nacional. Por ello, indicaba el Dr. Juan Marconi, había que medir "las consecuencias que el alcoholismo trae a la sociedad en general, el número de horas de trabajo perdidas, la proporción de accidentes de todo tipo que ocurren en estado de ebriedad, la criminalidad latente que el alcoholismo saca a luz, la desorganización de la familia, etc.” (Marconi, 1952, p. 17). Lo cual encontraba, a su entender, una explicación cultural, pues "en nuestro pueblo la embriaguez después del pago del salario se considera como parte de la rutina semanal, así como la que sigue a toda clase de fiestas y reuniones" (Marconi, 1952, p. 12). Poco después, los doctores Jorge Mardones y Aníbal Varela, del Instituto de Investigaciones sobre Alcoholismo y Clínica Psiquiátrica de la Universidad de Chile, sostendrían que "el alcohol es capaz de despertar en los individuos una dependencia psíquica, lo 
que constituye el motivo fundamental de diversas formas de su consumo habitual" (Mardones; Varela, 1956-57, p. 83).

Estos perfiles ratificaban, a partir de la individualidad de casos, la definición de la anormalidad no solo como la manifestación evidente de carencias físicas y mentales, que hacía especiales a ciertas personas, sino además su peligrosidad presente y futura, con claras repercusiones en el progreso del país. De ahí que fuese preciso resocializarlos/regenerarlos por una institucionalidad que el Estado, por su papel asistencial en este período, permitía implementar y financiar. Eran identidades no deseadas cuya opción era el tratamiento, la reincorporación o el encierro; en aras de mantener un modelo social y de productividad ante el cual los anormales mostraban una clara desconexión.

\section{Conclusiones}

A lo largo del período aquí examinado, es posible apreciar que la representación construida de la anormalidad en las páginas de la $R P D C$, y de los anormales en particular, no fue muy diferente a las ideas, discursos, creencias y estereotipos gestados en la época desde el poder político, el derecho y la criminología. En tal sentido, la psiquiatría, con el respaldo del positivismo aún vigente para entonces, aportó a dicha representación el énfasis en una base biológica y hereditaria que reforzó los sentidos comunes ya elaborados al momento de identificar, definir, clasificar, vigilar y controlar a quienes fueron adscritos a tal categorización o etiquetamiento. No obstante, los psiquiatras o al menos los frecuentes colaboradores de la revista fueron más que técnicos vinculados a una institución en particular para atender o resolver casos puntuales, pues fue a partir de la población de las instituciones asistenciales, psiquiátricas y penales que estos buscaron generar conocimiento sobre aquellas figuras inquietantes que eran vistas y percibidas en función de su peligrosidad real o virtual. En dicha tarea se encargaron de investigar, analizar y definir muestras para estudios grupales o presentar historias clínicas particulares que, al fin y al cabo, más que cuestionar o presentar una interpretación alternativa, tendieron a confirmar las asociaciones establecidas entre pobreza, criminalidad, vicios y violencia. De ahí que nunca se expusiera la ficha clínica de alguien que, presentando trastornos conductuales o expresiones de violencia explícita, perteneciera a una condición social más acomodada. 
Las distintas investigaciones reproducidas en la revista entregaron una interpretación binaria de la realidad psiquiátrica, médica y social a partir de polos opuestos como los de normalidad y anormalidad, lo sano y lo enfermo, lo deseable y lo peligroso; dotando de identidad e inteligibilidad a la anormalidad (como categoría o etiqueta) y a los anormales (como sujetos definidos y definidores a la vez de dicha categorización). Por supuesto, esta díada respondía a un proceso político, a un poder y a un saber científico (Foucault, 2000) que iba de la mano con las ideas de época de defensa social, higiene mental, estado peligroso, degeneración y depuración que, aunque en distintos niveles de figuración e impacto, ayudaron igualmente a construir una otredad que fue diagnosticada, analizada y publicitada. En dicha tarea fue crucial contar no solo con una mayor madurez y desarrollo de la especialidad psiquiátrica, sino también con una cultura profesional que tomó fuerza con el paso de los años y que puede ser pesquisada a partir de la revisión de las páginas de la $R P D C$, en particular al momento de examinar su carácter transnacional, la generación de discursos con sentidos para públicos variados, la existencia de soportes institucionales y de difusores legitimados en diferentes escenarios. De este modo, la anormalidad y la psiquiatría se vieron vinculadas por ideas de distinta naturaleza y llegada, así como por un modelo político y sociocultural que asoció lo diferente a lo prohibido y dañino, con aquello que alteraba el orden deseado perjudicando la vida, la propiedad y el desarrollo. Por dichas razones, y aunque se explicitara desde la revista la generación de un conocimiento científico y objetivo, dicho conocimiento fue, al fin y al cabo, un constructo histórico, no libre de subjetividades ni intereses, y estrechamente vinculado con las condiciones de la época en que fue forjado y transmitido.

\section{REFERENCIAS}

AGÜERO, Guillermo; CUBILLOS, Luis. Consideraciones sobre clínicas de higiene mental infantil y delincuencia. Revista de Psiquiatría y Disciplinas Conexas, Santiago, n. 10, pp. 38-50, 1938.

AGÜERO, Guillermo; CUBILLOS, Luis. Psiquiatría e higiene mental. Curso superior y elemental. Santiago: Imprenta de la Dirección General de Prisiones, 1941.

ARAYA I., Claudia. La locura es nuestra. Profesionalización de la Psiquiatría en Chile: saberes y prácticas (1826-1949). Rosario: Prohistoria Ediciones, 2018. 
ARROYO A., Víctor. Contribución al estudio de la alucinación y del delirio. Alcoholismo crónico, hipovitaminosis e hidatidosis múltiple y síndrome alucinatorio-delirante. Revista de Psiquiatría y Disciplinas Conexas, Santiago, año VI, n. 1-2, pp. 27-45, 1941.

BARRIENTOS, Juvenal; SCHIRMER, Edgardo. Consideraciones generales sobre antropología constitucional. Revista de Psiquiatría y Disciplinas Conexas, Santiago, n. 3-4, pp. 101-119, 1941.

BECA, Manuel. La herencia en psiquiatría. Revista de Psiquiatría y Disciplinas Conexas, Santiago, n. 9, pp. 12-30, 1938.

BECA, Manuel. Psicoanálisis y criminología. Revista de Psiquiatría y Disciplinas Conexas, Santiago, n. 3-4, pp. 409-432, 1940.

BECA, Manuel; LARRAGUIBEL, Aida. Observaciones médico-pedagógicas en niños mongoloides. Revista de Psiquiatría y Disciplinas Conexas, Santiago, n. 1-2, pp. 3-10, 1948.

BECKER, Howard Saul. Outsiders: hacia una sociología de la desviación. Buenos Aires: Siglo XXI Ed., 2009 [1963].

BOURDIEU, Pierre. Las condiciones sociales de la circulación de las ideas. In: Intelectuales, política y poder. Buenos Aires: Eudeba, 1999.

BRÜCHER, Eduardo. El psicodiagnóstico de Rorschach en delincuentes homosexuales. Revista de Psiquiatría y Disciplinas Conexas, Santiago, n. 3-4, pp. 92-100, 1941.

BUSTOS R., Juan. Estado y control: la ideología del control y el control de la ideología. In: BERGALLI, Roberto et al. El pensamiento criminológico II: Estado y control. Bogotá: Editorial Temis, 1983. pp. 11-35.

CAMARGO, Ricardo; RIED, Nicolás. La invención del toxicómano como sujeto a corregir. La figura del toxicómano en la producción discursiva farmacéutica chilena de la primera mitad del siglo XX. Universum, Talca: Universidad de Talca, vol. 34, n. 1, pp. 65-94, 2019.

CANGUILHEM, Georges. Lo normal y lo patológico. Buenos Aires, Argentina: Siglo XXI Ed., 1971.

CARRILLO, C.; RODRÍGUEZ, Sergio. Esquizofrenia paranoidea. Revista de Psiquiatría y Disciplinas Conexas, Santiago, n. 1-2, pp. 75-86, 1950.

CARRILLO, C.; WHITTING, Carlos. Un caso de homosexualidad. Revista de Psiquiatría y Disciplinas Conexas, Santiago, n. 1-2, pp. 129-141, 1952.

CASTEL, Robert. El orden psiquiátrico. Edad de oro del alienismo. Buenos Aires: Editorial Nueva Visión, 2009.

CORREA, María José. Cuerpo y demencia. La fisonomía de la incapacidad en Santiago de Chile (1855-1900). Historia Crítica. Bogotá, n. 46, pp. 88-109, 2012.

CUBILLOS, Luis; DRAPKIN, Israel. Importancia y valor real de los servicios de observación médico-criminológicos en la nueva técnica penitenciaria. Actas de la 
primera reunión de las Jornadas Neuro-Psiquiátricas Panamericanas. Santiago: Prensas de la Universidad de Chile, 1938.

CUBILlOS, Luis. El problema del niño anormal. Revista de Psiquiatría y Disciplinas Conexas, Santiago, n. 2, pp. 96-98, 1946.

DOVIO, Mariana. El caso de la "mala vida", peligrosidad y prevención de conductas marginales en Revista de Criminología, Psiquiatría, Medicina Legal y Ciencias Afines, en Buenos Aires, 1914-1923. História, Ciências, Saúde-Manguinhos, Rio de Janeiro, v. 20, supl., pp. 1225-1252, 2013.

EDITORIAL. Revista de Psiquiatría y Disciplinas Conexas, Santiago, n. 1, p. 1, 1935.

ESCOBAR, Enrique. La primera revista chilena de Psiquiatría, Neurología y Medicina Legal. Revista Médica de Chile, Santiago, n. 127 (3), pp. 366-370, 1999.

FACCHINETTI, Cristiana; CUPELLO, Priscila; EVANGELISTA, Danielle Ferreira. Arquivos Brasileiros de Psiquiatria, Neurologia e Ciências Afins: uma fonte com muita história. História, Ciências, Saúde-Manguinhos, Rio de Janeiro, v. 17, supl. 2, pp. 527-535, 2010.

FOUCAULT, Michel. Enfermedad mental y personalidad. Barcelona: Ediciones Paidós, 1991.

FOUCAULT, Michel. Los anormales: curso en el Collège de France (1974-1975). México: Fondo de Cultura Económica, 2000.

HOCHMAN, Gilberto; ARMUS, Diego (Orgs.). Cuidar, controlar, curar: ensaios históricos sobre saúde e doença na América Latina e Caribe. Coleção História e Saúde. Rio de Janeiro: Editora Fiocruz, 2004.

HORVITZ, Isaac. Contribución de los seguros sociales a la higiene mental. Revista de Psiquiatría y Disciplinas Conexas, Santiago, n. 2, pp. 10-18, 1936.

HORVITZ, Isaac. Actas de la primera reunión de las jornadas neuro-psiquiátricas panamericanas. Santiago: Prensas de la Universidad de Chile, 1938.

HUERTAS, Rafael. Historia cultural de la psiquiatría. Madrid: Los libros de la Catarata, 2012.

ITURRA, Waldo. Consideraciones clínicas y médico-legales sobre un caso de rabia curado. Revista de Psiquiatría y Disciplinas Conexas, Santiago, n. 4, pp. 43-56, 1936.

ITURRA, Waldo. La constitución perversa y la responsabilidad. Revista de Psiquiatría y Disciplinas Conexas, Santiago, n. 3-4, pp. 402-408, 1940.

KRIGE, John. Hybrid Knowledge: The Transnational Coproduction of the Gas Centrifuge for Uranium Enrichment in the 1960s. The British Journal for the History of Science, v. 45, issue 3 - Special Issue, pp. 337-357, 2012.

LEÓN, Marco Antonio. Construyendo un sujeto criminal. Criminología, criminalidad y sociedad en Chile: siglos XIX y XX. Santiago: Editorial Universitaria-DIBAM, 2015.

LETELIER C., Javiera. "Gobernar es poblar...seleccionadamente". Ideas eugenésicas en Chile 1925-1941: Una mirada científica y política hacia los intentos por mejorar "la 
raza chilena". Tesina (Grado Académico de Licenciada en Historia) - Facultad de Filosofía y Humanidades, Departamento de Historia. Universidad Alberto Hurtado. Santiago, 2009.

MALLEREAL, Jorge. La medicina: historia, saber y poder. El higienismo como dispositivo de defensa social. In: PALMA, Héctor A.; PARDO, Rubén H. (Eds.). Epistemología de las Ciencias Sociales. Buenos Aires: Editorial Biblos, pp. 249-273, 2012.

MARCONI, Juan. Alcoholismo: enfoque actual de la enfermedad en Chile. Revista de Psiquiatría, Santiago, n. 1-2, pp. 5-18, 1952.

MARCONI, Juan et al. Encuesta sobre la prevalencia del alcoholismo en una población de una zona de Santiago. Revista de Psiquiatría, Santiago, v. 18-20, pp. 11-16, 1953-1955.

MARCONI, Juan. El análisis factorial en el estudio de la personalidad normal y anormal. Revista de Psiquiatría, Santiago, v. 21-22, pp. 6-22, 1956-1957.

MARDONES, Jorge; VARELA, Aníbal. Enfoque farmacológico de las toxicomanías y en especial del alcoholismo. Revista de Psiquiatría, Santiago, v. 21-22, pp. 83-88, 1956-1957.

MIRANDA, Marisa; GIRÓN S., Álvaro (Coords.). Cuerpo, biopolítica y control social: América Latina y Europa en los siglos XIX y XX. Buenos Aires: Siglo XXI Ed., 2009. OSSANDÓN B., Carlos; SANTA CRUZ A., Eduardo. El estallido de las formas: Chile en los albores de la "cultura de masas". Santiago: LOM Ediciones, 2005.

PESET, José Luis. Ciencia y marginación: sobre negros, locos y criminales. Barcelona: Editorial Crítica, 1983.

PICK, Daniel. Faces of Degeneration: a European Disorder, c. 1848 - c. 1918. Cambridge: Cambridge University Press, 1999.

RAJ, Kapil. Relocating Modern Science: Circulation and the Construction of Knowledge in South Asia and Europe, 1650-1900. Houndmills; New York: Palgrave Macmillan, 2007.

RÍOS M., Andrés. Cómo prevenir la locura. Psiquiatría e higiene mental en México, 1934-1950. México: Siglo XXI Ed., 2016.

RODRÍGUEZ, Sergio. La mímica en la esquizofrenia. Revista de Psiquiatría y Disciplinas Conexas, Santiago, n. 1, pp. 3-80, 1943.

RODRÍGUEZ, Sergio. La demencia como entidad clínica. Revista de Psiquiatría y Disciplinas Conexas, Santiago, n. 1-2, pp. 3-33, 1952.

RUPERTHUZ, Mariano. Freud y los chilenos. Un viaje transnacional (1910-1949). Santiago: Pólvora Editorial, 2015.

SCULL, Andrew. Locura y civilización. Una historia cultural de la demencia, de la Biblia a Freud, de los manicomios a la medicina moderna. México: Fondo de Cultura Económica, 2019. 
VÁSQUEZ R., Adolfo. Foucault; "Los Anormales", una genealogía de lo monstruoso. Apuntes para una historiografía de la locura. Nómadas. Revista Crítica de Ciencias Sociales y Jurídicas, vol. 34, n. 2, pp. 403-420, 2012.

VERGARA, Adriana; HORVITZ, Isaac. Homicidio patológico y responsabilidad penal. Revista de Psiquiatría y Disciplinas Conexas, Santiago, n. 2, pp. 115-121, 1945.

VETÖ HONORATO, Silvana. Disputas por el dominio del alma. Historia cultural del psicoanálisis en Chile, 1910-1950. Tesis (Grado de Doctora en Historia) - Universidad de Chile. Santiago, 2015.

VILA, Gustavo. Proyecto sobre el problema asistencial de la infancia y juventud. Revista de Psiquiatría y Disciplinas Conexas, Santiago, n. 3, pp. 181-190, 1939.

VIVADO, Arturo; LARSON, C.; ARROYO, Víctor. La asistencia psiquiátrica en Chile. Revista de Psiquiatría y Disciplinas Conexas, Santiago, n. 3, pp. 155-174, 1939.

Artigo submetido em 29 de outubro de 2020.

Aprovado em 13 de abril de 2021.

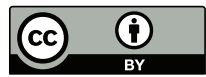

